\title{
Fatness QTL on chicken chromosome 5 and interaction with sex
}

\author{
Behnam ABASHT ${ }^{\mathrm{a}}$, Frédérique PITEL ${ }^{\mathrm{b}}$, Sandrine LAGARRIGUE ${ }^{\mathrm{a}}$, \\ Elisabeth LE BIHAN-DUVAL ${ }^{\mathrm{c}}$, Pascale LE ROY ${ }^{\mathrm{a}, \mathrm{d}}$, \\ Olivier DEMEURE ${ }^{\mathrm{a}}$, Florence VIGNOLES ${ }^{\mathrm{b}}$, Jean SIMON ${ }^{\mathrm{c}}$, \\ Larry CoGBURN ${ }^{\mathrm{e}}$, Sammy AGGREY ${ }^{\mathrm{f}}$, Alain VIGNAL ${ }^{\mathrm{b}}$, \\ Madeleine DOUAIRE ${ }^{\mathrm{a} *}$ \\ ${ }^{a}$ UMR Inra-Agrocampus Génétique animale, 35042 Rennes, France \\ ${ }^{\mathrm{b}}$ Laboratoire de génétique cellulaire, Inra, 31326 Auzeville, France \\ ${ }^{\mathrm{c}}$ Station de recherches avicoles, Inra, 37380 Nouzilly, France \\ ${ }^{d}$ SGQA, Inra, 78352 Jouy en Josas, France \\ ${ }^{\mathrm{e}}$ Department of Animal and Food Sciences, University of Delaware, Newark DE 19717, USA \\ ${ }^{\mathrm{f}}$ University of Georgia, Athens, GA 30602, USA
}

(Received 5 October 2005; accepted 8 December 2005)

\begin{abstract}
Quantitative trait loci (QTL) affecting fatness in male chickens were previously identified on chromosome 5 (GGA5) in a three-generation design derived from two experimental chicken lines divergently selected for abdominal fat weight. A new design, established from the same pure lines, produced $407 \mathrm{~F} 2$ progenies (males and females) from 4 F1-sire families. Body weight and abdominal fat were measured on the $\mathrm{F}_{2}$ at $9 \mathrm{wk}$ of age. In each sire family, selective genotyping was carried out for 48 extreme individuals for abdominal fat using seven microsatellite markers from GGA5. QTL analyses confirmed the presence of QTL for fatness on GGA5 and identified a QTL by sex interaction. By crossing one F1 sire heterozygous at the QTL with lean line dams, three recombinant backcross 1 (BC1) males were produced and their QTL genotypes were assessed in backcross 2 (BC2) progenies. These results confirmed the QTL by sex interaction identified in the F2 generation and they allow mapping of the female QTL to less than $8 \mathrm{Mb}$ at the distal part of the GGA5. They also indicate that fat QTL alleles were segregating in both fat and lean lines.
\end{abstract}

meat-type chickens / quantitative trait loci / fatness QTL / QTL $\times$ sex interaction

\section{INTRODUCTION}

In meat-type chickens, deposition of excessive adipose tissue decreases both feed efficiency and yield of lean meat. Fatness is a complex trait controlled by

${ }^{*}$ Corresponding author: Madeleine.Douaire@ rennes.inra.fr 
an unknown number of genes [35]. The identification of genes responsible for fat deposition could improve meat-chicken production through the breeding process and it would meet the consumer demand for leaner meat. Additionally, the identification of genes associated with excessive fattening could lead to a better understanding of the fundamental genetic mechanisms underlying the development of obesity in other species, including humans.

Quantitative trait loci (QTL) mapping has been extensively used as the first step in genetic dissection of complex traits $[13,32]$. In chicken, various experimental designs have been used for the identification of at least 26 fatness QTL [24, 26, 29, 42]. However, these results were all issued from first attempts in mapping fatness QTL, which encompass QTL regions spanning tens of centiMorgans (cM).

Further experiments are needed to refine these QTL and to identify the genes responsible for expression of production traits. For example, Jennen et al. [27] used the advanced intercross line method to reduce fatness QTL locations on chicken chromosome 1 from about $145 \mathrm{cM}$ in the first assessement to less than $25 \mathrm{cM}$ and $60 \mathrm{cM}$, respectively. Several approaches have been suggested for improving QTL map resolution [9]. The recombinant progeny testing method is one of the most commonly used to refine QTL regions [6]. This method identifies, among the relatives (usually offspring) of an animal known to be heterozygous for QTL, those individuals which carry recombination in the QTL chromosomal region compared to the chromosome of their QTL heterozygous parent. The recombinant animals are further evaluated for their QTL status through progeny testing $[8,9,21]$ which leads to physical dissection of the QTL region.

Following the primary identification of fatness QTL on chromosome 5 in a three-generation cross between experimental fat and lean lines [29], the present paper reveals new QTL results in the same lines, five generations later. In the new design, fatness was measured in both males and females which allowed detection of the QTL by sex interaction. This interaction was found in further back-cross generations in which recombinant events allowed the female QTL to be mapped to $<8 \mathrm{Mb}$ at the distal part of the GGA5.

\section{ANIMALS, MATERIALS AND METHODS}

\subsection{Animals and phenotypic data}

A three-generation design was performed by inter-crossing two experimental meat-type chicken lines that were divergently selected on fatness [30] referred to as the fat (FL) and lean (LL) lines. F1 birds were generated from 
FL $\sigma^{\prime \prime} \times$ LL $q$ and LL $\sigma^{\prime \prime} \times$ FL $q$ matings. Two F1 males from each of the reciprocal cross were each mated to 9-10 females from other unrelated families of the same cross. A total of 407 F2 chicks in 39 full-sib families were obtained in four hatches. In order to refine the QTL mapping, 81 back-cross 1 (BC1) males were produced from one QTL heterozygous F1 male (issued from FL $\times$ LL cross) mated to $10 \mathrm{LL}$ females. Three of the $\mathrm{BC} 1$ animals carrying paternal GGA5 recombinant in the QTL region were progeny tested for fatness QTL. The progeny were half and full-sib sire families of 110-136 BC2 animals (males and females) obtained in four hatches by mating the three recombinant BC1 males each to 7-11 LL females. Blood was collected from all the animals for DNA analyses.

The F2 and BC2 chickens were fed ad libitum using a conventional starter (0-3 weeks) diet (12.8 MJ of metabolisable energy) and then a growing (4-9 weeks) diet (13.0 MJ of metabolisable energy). Light/dark periods were 24h light for the first 2 days, then 14h light/10h night up to slaughtering. At 9 weeks of age, the birds were weighed after an overnight fast and then killed by electrical stunning in the experimental processing plant (Station de recherches avicoles, Inra, Nouzilly, France). After evisceration, carcasses were stored overnight at $4{ }^{\circ} \mathrm{C}$ before dissection and weighing of abdominal fat.

\subsection{Markers and genotyping}

Genomic DNA was purified from individual blood samples $(100 \mu \mathrm{L})$ using the usual phenol/chloroform extraction method modified for large sample numbers [2]. It was quantified by the saran method [37] and diluted to $10 \mathrm{ng} / \mu \mathrm{L}$.

Microsatellite markers on GGA5 were chosen from the genetic consensus map $[18,39]$ based on their location on the chromosome and their informativity in each sire family. Fluorescently labelled microsatellite sequences were analysed on an ABI 3700 DNA sequencer (Applied Biosystems, Foster City, CA, USA) and their lengths were determined using GeneScan Analysis ${ }^{\mathrm{TM}}$ software (Applied Biosystems, Foster City, CA, USA). Genotypes were interpreted using both the Genotyper Analysis ${ }^{\mathrm{TM}}$ software (Applied Biosystems, Foster City, CA, USA) and GEMMA databases [23].

New markers were developed to refine the QTL location and the position of recombination events. Among the microsatellite markers identified on the chicken genome sequence (http://www.ensembl.org/Gallus_gallus/) four were chosen for their informativity in the present families and their convenience. They were SEQ0079, SEQ0081, SEQ0082, SEQ0085, with EMBL accession numbers AM040172, AM040174, AM040175, AM040177, respectively. 
SSCP (single strand conformational polymorphism) markers were developed from expressed sequence tags (EST) localised on the GGA5 radiation hybrid map [34] with the same primer sequences and PCR conditions. QTL heterozygous F1 sires and their F0 parents were examined for polymorphisms using SSCP analyses [2].

In the F2, a genetic map was obtained using the CRI-MAP linkage programme ("build" option) with marker distances in Kosambi centiMorgans (cM) [16]. The actual distances in the families were used in the F2 QTL analyses. They were in accordance with those of the consensus map [39]. In the BC2 generation, the consensus genetic map was used because the number of informative meiosis was too low to ensure reliable distance assessment. Genetic distances were expressed either in $\mathrm{cM}$ or in bp, according to the chicken genome sequences.

Regarding the QTL analyses, selective genotyping was carried out on 192 F2 animals, their $30 \mathrm{~F} 1$ parents and $27 \mathrm{~F} 0$ grand-parents using seven GGA5 microsatellite markers (Fig. 1). Only 48 F2 animals with the most extreme values (i.e., the 24 highest and the 24 lowest) in each F1 sire family for adjusted abdominal fat weight (see below) were used for the analysis. Offspring from dams which were not roughly equally represented in both extreme groups were ignored. For the BC2 generation, 380 animals and their 26 parents and grand-parents were genotyped using six GGA5 microsatellite markers (Fig. 1).

\subsection{Statistical analyses}

For the F2 animals, abdominal fat weights were adjusted for sire, dam (within sire), sex, and hatching group effects using the SAS ${ }^{\circledR}$ GLM procedure [38] with 9-week body weight as a covariate. In the $\mathrm{BC} 2$ generation, the phenotypic data were similarly adjusted in each sire family for dam and sex effects, without hatch group correction since hatch groups were not significantly different. Data adjustment was done prior to the QTL analyses in order to identify those animals with extreme values in each family.

QTL interval mapping was performed using QTL express software [40] with three different models: line-cross and half-sib models were used in the F2 generation, whereas a back-cross model was used for analyses of the $\mathrm{BC} 2$ generation.

In the line-cross model, the probability for an $\mathrm{F} 2$ animal to be one of the following QTL genotypes (QQ, Qq, qQ, and qq) was calculated at $1 \mathrm{cM}$ intervals on GGA5, conditionally to the marker genotypes. Coefficients for additive $\left(c_{a}\right)$ 
a

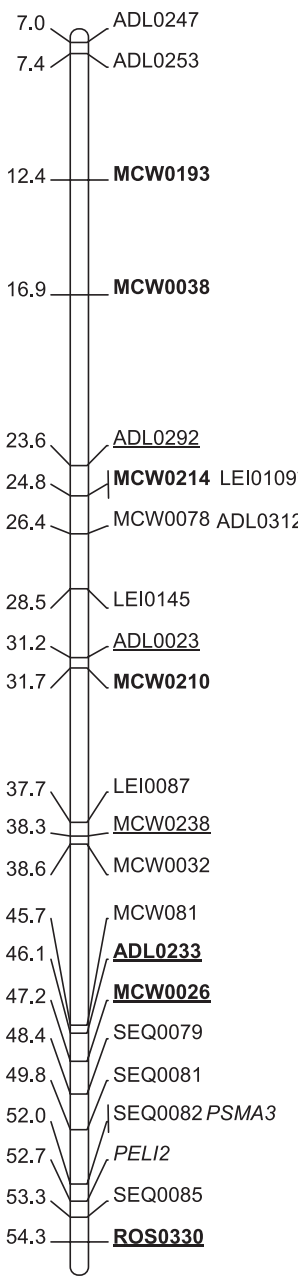

1

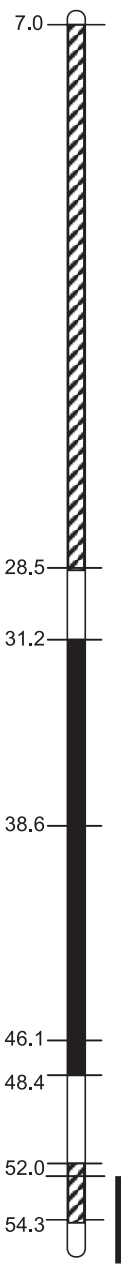

2

3

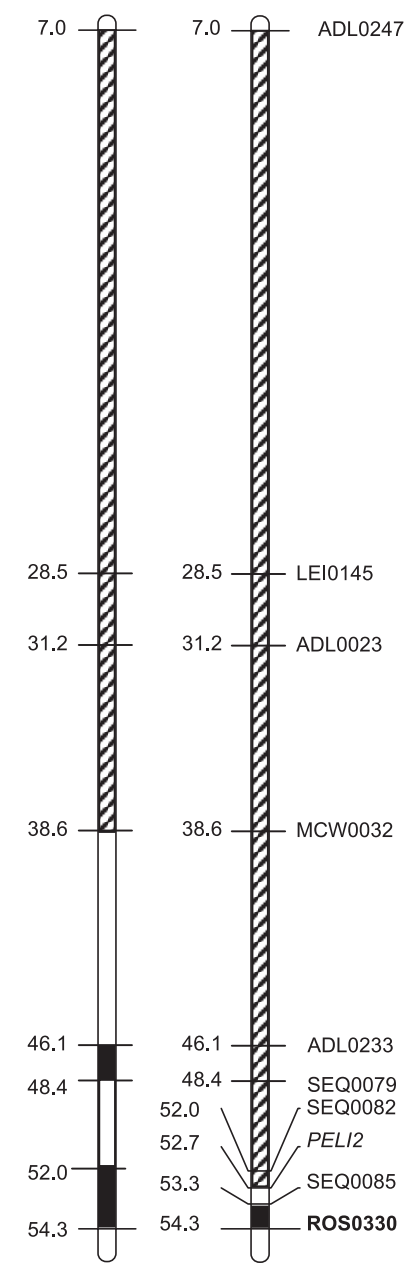

Figure 1. GGA5 genetic map and $\mathrm{BC} 1$ haplotypes originating from their $\mathrm{F} 1$ sires. a: Genetic markers used for genotyping. Markers in bold letters were used in the F1 QTL analyses. Underlined markers were used in the BC1 QTL analyses. New SSCP markers are presented in italics. *These markers were not assembled in the chicken sequence map; they have been located relative to other markers on the consensus genetic map [17]. Distances are shown in Mb. 1, 2, 3: Sire-originating haplotypes of BC1 recombinant males 1, 2 and 3, respectively. Black boxes: Fat Line origin. Striped boxes: Lean Line origin. Hollow boxes: not characterised, may contain a recombination break point. The thick line close to the sire 1 recombinant haplotype indicates the possible location of female-QTL. 
and dominance $\left(c_{d}\right)$ components were calculated at each position. $\operatorname{Prob}(\mathrm{XX})$ being the probability for each individual to have an $\mathrm{XX}$ genotype, $c_{a}$ is equal to $\operatorname{prob}(\mathrm{QQ})$ - prob(qq) and $c_{d}$ is equal to $\operatorname{prob}(\mathrm{Qq}$ and $\mathrm{qQ})$, where $\mathrm{Q}$ and $\mathrm{q}$ are two QTL alleles. In the next step, the adjusted phenotypic data were regressed onto these coefficients. Quoting the effect of QQ, Qq and qq as $a, d$ and $-a$, respectively [14], the additive $(a)$ and dominance effects $(d)$ of putative QTL at a given location can be estimated using the following model:

$$
y_{i}=m+c_{a i} a+c_{d i} d+e_{i}
$$

where $y_{i}$ is the adjusted phenotypic value of animal $i, m$ is the general mean, $c_{a i}$ and $c_{d i}$ are, respectively, the coefficients for the additive and dominant components for that individual $i$ at the given location, and $e_{i}$ is the residual error. The sign of the additive component indicates which line carries which QTL allele (high or low). QTL by sex interaction was investigated using the appropriate model. When using the half-sib model, the F2 animals were considered as four independent half-sib families. The allele substitution effect was fitted within each sire family.

The back-cross option of QTL express software was applied when analysing the three $\mathrm{BC} 1$ recombinant sires and their BC2 progenies. This option is used to determine which haplotype is associated with which QTL allele (high or low).

Chromosome-wide significant thresholds for the presence of a QTL were determined empirically by permuting marker data, as described by Churchil and Doerge [7]. Thresholds were obtained from 1000 permutations and are presented as $F_{0.05}$ and $F_{0.01}$ for significance at $\alpha=0.05$ and $\alpha=0.01 \mathrm{lev}$ els, respectively. Confidence intervals for QTL location were calculated from 1000 bootstrap samples [43].

\section{RESULTS}

QTL for abdominal fat weight at 9-weeks of age adjusted for sex and body weight (AF) was investigated on GGA5 in F2 and back-cross generations.

\subsection{F2 generation analyses: QTL by sex interaction}

Single QTL analysis with the line-cross model was performed in 192 F2 animals (males and females) with extreme AF values in each of the four F1 sire progeny. No significant QTL was detected (Fig. 2), however, a test comparing 


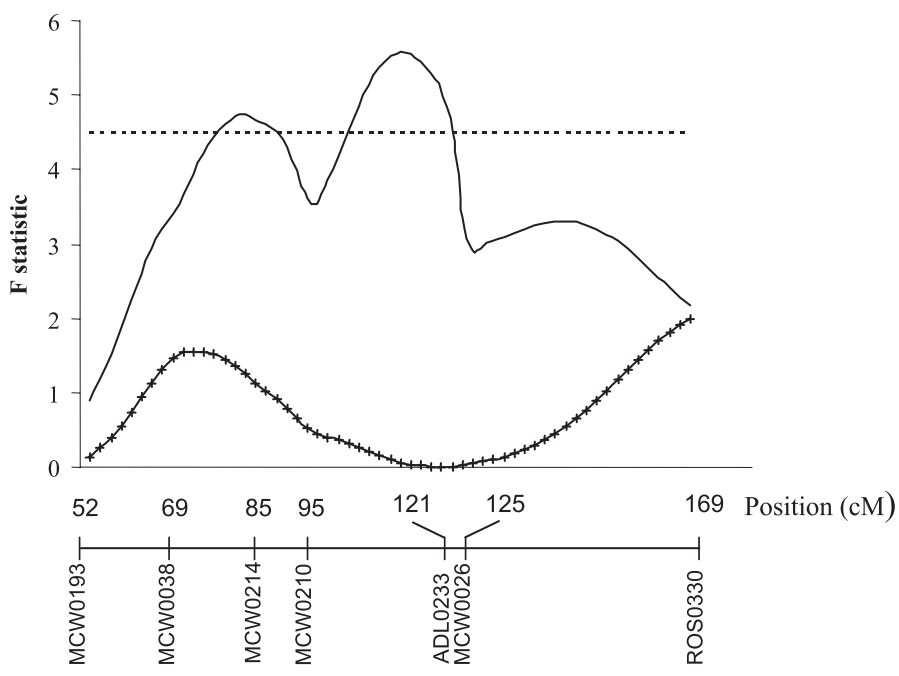

Figure 2. Fatness QTL analyses along GGA5 in F2 progenies (males and females together). The crossed line shows the test statistic values for the line-cross model [40]. The solid line shows the test statistic values for the same model including QTL by sex interaction. The horizontal line shows the chromosome-wide significant threshold $(p<0.05)$. The genetic markers used in the analyses are shown under the $\mathrm{X}$-axis. The genetic distances were assessed in the present design.

a single QTL interacting with sex versus no QTL led to the detection of a significant QTL $(p<0.05)$ at $112 \mathrm{cM}$ (Fig. 2).

QTL analyses performed within each sex separately showed a significant QTL ( $p<0.05$ chromosome-wide) in males at $80 \mathrm{cM}$ and a suggestive QTL ( $p<0.07$ chromosome-wide) in females at $116 \mathrm{cM}$ (Tab. I). The estimated additive effects of QTL were of the same magnitude in both sexes ( 0.4 and 0.5 phenotypic standard deviation in males and females, respectively) but with opposite signs (Tab. I). In this case, the high QTL allele (allele with the higher value) came from the FL haplotype in males and from the LL haplotype in females.

There was no evidence of imprinting, multiple QTL or QTL with dominance effect in either type of analyses.

QTL interval mapping was also investigated with the half-sib procedure of QTL express software in order to test each F1 sire as for its heterozygosity at the QTL. Similarly to the line-cross model, these analyses did not detect any significant QTL when the sexes were analysed together. When performed within each sex separately, and all the 4 sire-families together, half-sib QTL analyses identified a significant male fatness QTL at $72 \mathrm{cM}$, whereas the 
Table I. Location and effects of fatness QTL on GGA5 under the line-cross model in an F2 population derived from LL and FL.

\begin{tabular}{cccccc}
\hline Sex & F ratio $^{\mathrm{a}}$ & Position $(\mathrm{cM})^{\mathrm{b}}$ & Flanking markers & $\begin{array}{c}\text { Additive effect } \\
(\mathrm{SE})^{\mathrm{c}}\end{array}$ & $\begin{array}{c}\% \\
\text { Variance }^{\mathrm{d}}\end{array}$ \\
\hline Male & $7.04^{*}$ & $80(65-122)$ & MCW0038-MCW0214 & $8.41(3.17)$ & 7.56 \\
Female & $6.74^{+}$ & $116(70-166)$ & $M C W 0210-A D L 0233$ & $-10.00(3.85)$ & 12.55 \\
\hline
\end{tabular}

${ }^{\text {a }}$ For test of one vs. no QTL. ${ }^{+}, *$ Indicates significance at chromosome-wide $10 \%$ and $5 \%$ levels, respectively.

b $95 \%$ confidence interval in bracket; $\mathrm{cM}=$ centiMorgan.

c Additive effect was defined as half the difference between two homozygotes. $\mathrm{SE}=$ standard error.

${ }^{\mathrm{d}}$ Percentage of residual variance explained by the QTL.

significance level (5\%) was not reached in females. However, when performed within each sire family, the analyses showed a significant female-QTL in one family at $116 \mathrm{cM}$. As for the male-QTL two out of four F1 sire-families were segregating for a significant $(p<0.05)$ QTL located at $68-80 \mathrm{cM}$ according to the family. One of these F1 sires was heterozygous at both male and female QTL.

\subsection{Back-cross 2 generation analyses: refining QTL mapping}

QTL analyses were performed with the back-cross model of QTL express software. No significant QTL was found in either family when both sexes were analysed together, but significant sex-specific QTL were found when males and females were analysed separately (Tab. II). In one BC2 progeny (Family 1), a significant fatness QTL was identified in females but not in males, whereas in Family 2, a fatness QTL was segregating in males but not in females. In both cases, the most likely location of the QTL was at the distal part of the GGA5 (Fig. 1, Tab. II). No significant QTL was identified in Family 3, in either sex.

The magnitude of the QTL effects was similar in males and females $(0.98$ and 0.81 phenotypic standard deviation, Tab. II). In Sire 1, the QTL allele increasing fatness in females was carried by the paternal recombinant chromosome, whereas in Sire 2, the QTL allele increasing fatness in males was carried by the maternal LL chromosome.

The three $\mathrm{BC} 1$ males were carrying recombinant GGA5 from their $\mathrm{F} 1$ sire and LL GGA5 from their dams. A comparison of the LL or FL origins in the recombinant chromosomes carrying the QTL allele allowed us to locate the female-QTL between PELI2 and the chromosome end (i.e., less than $4 \mathrm{Mb}$ ) 
Table II. Location and effects of fatness QTL on GGA5 in three back-cross families under the back-cross model.

\begin{tabular}{|c|c|c|c|c|c|c|}
\hline Family & $\mathrm{N}^{\mathrm{a}}$ & Position $(\mathrm{cM})^{\mathrm{b}}$ & $\begin{array}{c}\text { Flanking } \\
\text { markers }\end{array}$ & F ratio $^{\mathrm{c}}$ & $\begin{array}{c}\text { QTL } \\
\text { effect }^{d}\end{array}$ & $\mathrm{SE}^{\mathrm{e}}$ \\
\hline \multicolumn{7}{|l|}{$\mathbf{1}$} \\
\hline Male \& Female & 136 & 167 & & 2.81 & 4.56 & 2.72 \\
\hline Male & 66 & 151 & & 2.19 & 4.05 & 2.73 \\
\hline Female & 70 & $192(87.5-198)$ & MCW0026-ROSO330 & $6.82 *$ & 9.35 & 3.58 \\
\hline \multicolumn{7}{|l|}{2} \\
\hline Male \& Female & 134 & 171 & & 6.03 & 5.25 & 2.14 \\
\hline Male & 71 & $181(146-198)$ & MCW0026-ROSO330 & $11.87 * *$ & 11.04 & 3.20 \\
\hline Female & 63 & 198 & & 2.63 & 3.32 & 2.05 \\
\hline \multicolumn{7}{|l|}{3} \\
\hline Male \& Female & 110 & 198 & & 0.81 & 2.11 & 2.35 \\
\hline Male & 53 & 163 & & 0.33 & 2.06 & 3.58 \\
\hline Female & 57 & 189 & & 1.90 & 4.78 & 3.46 \\
\hline
\end{tabular}

${ }^{\text {a }}$ Number of offspring.

${ }^{b}$ In brackets $95 \%$ confidence interval of the QTL position obtained by the bootstrap method.

c For test of one $v s$. no QTL. *, ** indicate significance at the chromosome wide 5\% and $1 \%$ level, respectively, based on 1000 permutation tests.

${ }^{\mathrm{d}}$ Absolute values of the allele, substitution effect.

${ }^{\mathrm{e}} \mathrm{SE}=$ standard error of QTL effect.

(Fig. 1). From the F2 analyses, the high female QTL allele was known to originate from the LL chromosome. In the $\mathrm{BC} 1$ Male 1 recombinant chromosome (carrying the high female QTL allele), the LL part could extend from SEQ0079 $(48.4 \mathrm{Mb})$ up to the distal end $(56.2 \mathrm{Mb})$, which means 7.8 $\mathrm{Mb}$. But in BC1 Male 3, carrying no QTL, the LL part of the paternal recombinant chromosome extended up to PELI2 (52.7 Mb), which would exclude this region for the QTL location. Then the QTL would be in the $3.5 \mathrm{Mb}$ beyond PELI2. However, one cannot rule out that the LL part of the $\mathrm{BC} 1$ Male 3 recombinant chromosome could actually carry the high female QTL allele which could be masked by the same allele carried by the maternal LL chromosome. This would keep the QTL region to $7.8 \mathrm{Mb}$.

The male-QTL could not be mapped with such accuracy. The QTL identified at $68 \mathrm{cM}$ in the F1 sire was not found in its back-cross progeny. Since none of the recombinant $\mathrm{BC} 1$ descendants carried the relevant chromosomal part (the FL proximal part of GGA5), one could speculate that the male-QTL was located in the missing region that is up to $31.2 \mathrm{Mb}$ (ADLO023). The location of the new male-QTL found at the distal end of the chromosome in BC1 Male 2 
could only rely on the estimated confidence interval $(52 \mathrm{cM})$, since the high allele came from a full LL chromosome.

\section{DISCUSSION}

This study confirmed the existence of fatness QTL on GGA5 as already reported in the FL and LL [29] and in other genetic backgrounds [24,31]. We discovered an interaction between QTL and sex, which gives rise to sex-specific QTL. In addition, the analyses of recombinant back-cross sires allowed us to refine the female-QTL to less than $8 \mathrm{Mb}$ at the distal end of GGA5.

When analysing a three-generation QTL design using a cross between divergent lines, the line-cross model should provide the best fit to the data. However, that model relies on the assumption that the different QTL alleles are fixed in each founder line [19], which is doubtful in the FL and LL. In fact not all the F1 sires were identified as QTL heterozygous, which was previously observed by [29]. When the founder lines are not totally fixed for these unique alleles, the method still proves very useful depending on allele effects and allele frequencies in both lines $[1,10]$. In the half-sib model, no assumption was made about the allele frequencies within the founder lines [28], although the estimates rely on less data since each family is considered individually. However, De Koning et al. [10] have shown that the half-sib and line-cross approaches have similar power when QTL effects are mainly additive, which was true in the present study. In the present F2 generation experiment, line-cross and halfsib models provided consistent results. No QTL was detected when the models were applied to data with sexes combined; however, QTL analyses within each sex led to significant effects and to similar QTL locations with both models.

The QTL by sex interaction and sex-specific QTL in the BC2 generation confirmed those found in the F2 analyses. Similar QTL with different or specific effects in males and females have been observed in other mapping studies on body composition QTL. For instance, Horvat et al. [22] detected a femalespecific QTL for fatness on MMU12 using a cross between lines divergently selected for fat content. Also in mice selected for high growth compared to a control line, three QTL were detected with sex-specific effects on abdominal fat weight [4]. Ishikawa et al. [25] found five sex-specific QTL with a main effect on body weight. A QTL by sex interaction could result from an opposite QTL effect according to the sex, which was the case presented by De Koning et al. [11] for meat quality traits in pigs. In broiler-type chickens, markers associated with a body weight QTL displayed alleles with different frequencies and different and even opposite effects in males and females [12]. 
From a biological point of view, QTL by sex interactions might be explained by genes with different effects in sexually different environments as suggested by Hamoen et al. [20]. More generally, the QTL by sex can be considered as a genotype by environment interaction, considering sex as an environment for the genotype expression. The same phenotypic measurement could then be considered as different traits in the sexes [33]. The concept is applicable to QTL by sex interaction and could have applications in utilising QTL in selection programmes.

A back-cross strategy was undertaken in order to refine the QTL location evidenced in the F2 generation. Such a design fits well into our current objective since only abdominal fat and one QTL region were under consideration. It is more productive to focus on particular recombinant breeders avoiding the risk of losing the QTL region when "blind-crosses" are made as in AIL (advanced intercross lines). In addition the step-wise procedure, using a few families in each generation, allows refining the location at every generation with a limited number of relevant animals reducing both genotyping and measurement costs, even if increasing the number of generations to meet the desired goal compared to a single back-cross generation with many recombinant breeders. Compared to an AIL procedure [27], this strategy can obtain the same precision regarding the QTL location in 3-4 back-cross generations instead of 8-10 generations.

The male-QTL found in F2 progeny was located at the proximal end of GGA5, with the high AF allele originating from the FL. It could not have been detected in the back-cross experiment since that FL chromosomal part was missing in the back-cross recombinant sires. Collectively, the results suggest that this QTL is located in the region of $0-31.2 \mathrm{Mb}$. The location of this QTL for fatness agrees with previous studies using either males of the FL and LL [29] or a broiler $\times$ layer cross [24].

In the back-cross generation, the male- and female-specific QTL were both located in the same region at the distal part of GGA5. As for the male-specific QTL, its location was similar to one already found in a previous experiment with the male trait only [29]. However, the high AF allele in the present case came from the LL, unlike the previous experiment. This could explain why this QTL was not found in the F2 generation, since the LL chromosome of the F1 sire was brought by another LL female which did not carry the fat allele. Similarly in females, the high AF allele originates from the LL. In this case, the same chromosomal fragment was involved in both $\mathrm{F} 1$ and $\mathrm{BC} 1$ sires leading to similar results which evidenced the female-specific QTL in an LL haplotype. High-fat alleles coming from a low-fat line are defined as transgressive variation [15]. Transgressive alleles have been identified in several comprehensive 
QTL scans for ovulation rate in swine [5], for backfat thickness in swine [3,36], for red colour and fruit size in tomatoes [41], for example. The present results confirm that, despite divergent selection, alleles that increase AF are still segregating in the LL.

Regarding the female-specific QTL, it could be localised in the $3.5 \mathrm{Mb}$ distal part of GGA5 (beyond PELI2) based on the aforementioned assumption in the Results paragraph. Without any assumption, it is localised in a $7.8 \mathrm{Mb}$ region at the end of GGA5 (beyond SEQ0079). Among the 140 genes located in this region (http//www.ensembl.org/Gallus_gallus/), some possible candidate genes are transcription factors $(B R F 1, T R I P-B r)$ and the estrogen receptor $(E S R)$. However, there is no direct evidence for their implication in the control of fatness variability in the chicken.

\section{ACKNOWLEDGEMENTS}

The authors acknowledge the valuable technical support provided by the experimental station and laboratory staff in the Station de Recherches Avicoles (Inra-Nouzilly), particularly N. Millet. They are grateful to the technical staff of the Laboratoire de Génétique Cellulaire (Inra-Toulouse) and the Unité de Génétique Animale (Inra-Agrocampus Rennes) for their technical support. Genotyping was realised in the Toulouse-Midi-Pyrénées Génopole ${ }^{\circledR}$ (France).

The production of $\mathrm{FL} \times \mathrm{LL} \mathrm{F1}$ and $\mathrm{F} 2$ chickens was funded by a USDA consortium grant to LC, SA and JS (USDA-IFAFS Animal Genome Program, Award Number 00-521009614). Otherwise the investigation was supported by the French Institute for Agricultural Research (Inra), the French Ministry of Agriculture (DGER), the Regional Council of Brittany and the Toulouse-Midi-Pyrénées Génopole ${ }^{\circledR}$. B. Abasht is a PhD student supported by the Iranian Ministry of Science, Research and Technology and by SFERE.

\section{REFERENCES}

[1] Alfonso L., Haley C.S., Power of different F2 schemes for QTL detection in livestock, Anim. Sci. 66 (1998) 1-8.

[2] Assaf S., Lagarrigue S., Daval S., Sansom M., Leclercq B., Michel J., Pitel F., Alizadeh M., Vignal A., Douaire M., Genetic linkage and expression analysis of SREBP and lipogenic genes in fat and lean chicken, Comp. Biochem. Phys. B 137 (2004) 433-441.

[3] Bidanel J.P., Milan D., Iannuccelli N., Amigues Y., Boscher M.Y., Bourgeois F., Caritez J.C., Gruand J., Le Roy P., Lagant H., Quintanilla R., Renard C., Gellin J., Ollivier L., Chevalet C., Detection of quantitative trait loci for growth and fatness in pigs, Genet. Sel. Evol. 33 (2001) 289-309. 
[4] Brockmann G.A., Haley C.S., Renne U., Knott S.A., Schwerin M., Quantitative trait loci affecting body weight and fatness from a mouse line selected for extreme high growth, Genetics 150 (1998) 369-381.

[5] Campbell E.M., Nonneman D., Rohrer G.A., Fine mapping a quantitative trait locus affecting ovulation rate in swine on chromosome 8, J. Anim. Sci. 81 (2003) 1706-1714.

[6] Christians J.K., Keightley P.D., Fine mapping of a murine growth locus to a 1.4-cM region and resolution of linked QTL, Mamm. Genome 15 (2004) 482-491.

[7] Churchill G.A., Doerge R.W., Empirical threshold values for quantitative trait mapping, Genetics 138 (1994) 963-971.

[8] Darvasi A., Interval-specific congenic strains (ISCS): an experimental design for mapping a QTL into a 1-centimorgan interval, Mamm. Genome 8 (1997) 163-167.

[9] Darvasi A., Experimental strategies for the genetic dissection of complex traits in animal models, Nat. Genet. 18 (1998) 19-24.

[10] de Koning D.J., Janss L.L., Rattink A.P., van Oers P.A., de Vries B.J., Groenen M.A., van der Poel J.J., de Groot P.N., Brascamp E.W., Van Arendonk J.A., Detection of quantitative trait loci for backfat thickness and intramuscular fat content in pigs (Sus scrofa), Genetics 152 (1999) 1679-1690.

[11] de Koning D.J., Harlizius B., Rattink A.P., Groenen M.A., Brascamp E.W., Van Arendonk J.A., Detection and characterization of quantitative trait loci for meat quality traits in pigs, J. Anim. Sci. 79 (2001) 2812-2819.

[12] Deeb N., Lamont S.J., Use of a novel outbred by inbred F1 cross to detect genetic markers for growth, Anim. Genet. 34 (2003) 205-212.

[13] Doerge R.W., Mapping and analysis of quantitative trait loci in experimental populations, Nat. Rev. Genet. 3 (2002) 43-52.

[14] Falconer D.S., Introduction to quantitative genetics, Longman, London; New-York, 1981.

[15] Frankel W.N., Taking stock of complex trait genetics in mice, Trends Genet. 11 (1995) 471-477.

[16] Green P., Falls K., Crooks S., Documentation for CRI-MAP version 2.4, Washington University School of Medicine, St Louis, MO, 1990.

[17] Groenen M.A., Crooijmans R.P., Veenendaal A., Cheng H.H., Siwek M., van der Poel J.J., A comprehensive microsatellite linkage map of the chicken genome, Genomics 49 (1998) 265-274.

[18] Groenen M.A., Cheng H.H., Bumstead N., Benkel B.F., Briles W.E., Burke T., Burt D.W., Crittenden L.B., Dodgson J., Hillel J., Lamont S., de Leon A.P., Soller M., Takahashi H., Vignal A., A consensus linkage map of the chicken genome, Genome Res. 10 (2000) 137-147.

[19] Haley C.S., Knott S.A., Elsen J.M., Mapping quantitative trait loci in crosses between outbred lines using least squares, Genetics 136 (1994) 1195-1207.

[20] Hamoen F.F., Van Kaam J.B., Groenen M.A., Vereijken A.L., Bovenhuis H., Detection of genes on the Z-chromosome affecting growth and feathering in broilers, Poult. Sci. 80 (2001) 527-534. 
[21] Hill W.G., Selection with recurrent backcrossing to develop congenic lines for quantitative trait loci analysis, Genetics 148 (1998) 1341-1352.

[22] Horvat S., Bunger L., Falconer V.M., Mackay P., Law A., Bulfield G., Keightley P.D., Mapping of obesity QTL in a cross between mouse lines divergently selected on fat content, Mamm. Genome 11 (2000) 2-7.

[23] Iannuccelli N., Wolosyn N., Arhainx J., Gellin J., Milan D., GEMMA: A database to automate microsatellite genotyping., Anim. Genet. 27 Suppl. 2 (1996) 55.

[24] Ikeobi C.O., Woolliams J.A., Morrice D.R., Law A., Windsor D., Burt D.W., Hocking P.M., Quantitative trait loci affecting fatness in the chicken, Anim. Genet. 33 (2002) 428-435.

[25] Ishikawa A., Matsuda Y., Namikawa T., Detection of quantitative trait loci for body weight at 10 weeks from Philippine wild mice, Mamm. Genome 11 (2000) 824-830.

[26] Jennen D.G., Vereijken A.L., Bovenhuis H., Crooijmans R.P., Veenendaal A., van der Poel J.J., Groenen M.A., Detection and localization of quantitative trait loci affecting fatness in broilers, Poultry Sci. 83 (2004) 295-301.

[27] Jennen D.G., Vereijken A.L., Bovenhuis H., Crooijmans R.M., van der Poel J.J., Groenen M.A., Confirmation of quantitative trait loci affecting fatness in chickens, Genet. Sel. Evol. 37 (2005) 215-228.

[28] Knott S.A., Elsen J.M., Haley C.S., Methods for multiple-marker mapping of quantitative trait loci in half-sib populations, Theor. Appl. Genet. 93 (1996) 71-80.

[29] Lagarrigue S., Pitel F., Carre W., Abasht B., Le Roy P., Néau A., Amigues Y., Sourdioux M., Simon J., Cogburn L.A., Aggrey S.E., Leclercq B., Vignal A., Douaire M., Mapping quantitative trait loci affecting fatness and breast muscle weight in meat-type chicken lines divergently selected on abdominal fatness, Genet. Sel. Evol. 38 (2006) 85-97.

[30] Leclercq B., Blum J.C., Boyer J.P., Selecting broilers for low or high abdominal fat: initial observations, Brit. Poultry Sci. 21 (1980) 107-113.

[31] Li H., Deeb N., Zhou H., Mitchell A.D., Ashwell C.M., Lamont S.J., Chicken quantitative trait loci for growth and body composition associated with transforming growth factor-beta genes, Poultry Sci. 82 (2003) 347-356.

[32] Lynch M., Walsh B., Genetics and analysis of quantitative traits, Sinauer Associates Inc, Sunderland, MA, 1998.

[33] Muir W.M., Aggrey S.E., Poultry genetics, breeding and biotechnology, CABI Publishing, 2003.

[34] Pitel F., Abasht B., Morisson M., Crooijmans R.P., Vignoles F., Leroux S., Feve K., Bardes S., Milan D., Lagarrigue S., Groenen M.A., Douaire M., Vignal A., A high-resolution radiation hybrid map of chicken chromosome 5 and comparison with human chromosomes, BMC. Genomics 5 (2004) 66.

[35] Pomp D., Genetic dissection of obesity in polygenic animal models, Behav. Genet. 27 (1997) 285-306.

[36] Rohrer G.A., Keele J.W., Identification of quantitative trait loci affecting carcass composition in swine: I. Fat deposition traits, J. Anim. Sci. 76 (1998) 2247-2254. 
[37] Sambrook J., Fritsch E.F., Maniatis T., Molecular cloning: a laboratory manual, Cold Spring Harbor Laboratory Press, New York, 1989.

[38] SAS ${ }^{\circledR}$ Institute, SAS ${ }^{\circledR} /$ STATO User's Guide, version 6, SAS ${ }^{\circledR}$ Institute Inc., Cary NC, 1989.

[39] Schmid M., Nanda I., Guttenbach M., Steinlein C., Hoehn M., Schartl M., Haaf T., Weigend S., Fries R., Buerstedde J.M., Wimmers K., Burt D.W., Smith J., A'Hara S., Law A., Griffin D.K., Bumstead N., Kaufman J., Thomson P.A., Burke T., Groenen M.A., Crooijmans R.P., Vignal A., Fillon V., Morisson M., Pitel F., Tixier-Boichard M., Ladjali-Mohammedi K., Hillel J., Maki-Tanila A., Cheng H.H., Delany M.E., Burnside J., Mizuno S., First report on chicken genes and chromosomes 2000, Cytogenet. Cell Genet. 90 (2000) 169-218.

[40] Seaton G., Haley C.S., Knott S.A., Kearsey M., Visscher P.M., QTL Express: mapping quantitative trait loci in simple and complex pedigrees, Bioinformatics 18 (2002) 339-340.

[41] Tanksley S.D., McCouch S.R., Seed banks and molecular maps: unlocking genetic potential from the wild, Science 277 (1997) 1063-1066.

[42] Tatsuda K., Fujinaka K., Genetic mapping of the QTL affecting body weight in chickens using a F2 family, Brit. Poultry Sci. 42 (2001) 333-337.

[43] Visscher P.M., Thompson R., Haley C.S., Confidence intervals in QTL mapping by bootstrapping, Genetics 143 (1996) 1013-1020.

To access this journal online: www.edpsciences.org 
